\title{
The Correlation between Teachers' Visual Digital Media Design Ability and Effective Teaching
}

\author{
https://doi.org/10.3991/ijet.v17i01.28717 \\ Lin Shao ${ }^{1}$, Wendi Zhang ${ }^{1}$, Aiping $\mathrm{Li}^{1}$, Feng $\operatorname{Xin}^{2}(\varpi)$ \\ ${ }^{1}$ Department of Art and Media, Hebei Vocational University of Technology and Engineering, \\ Xingtai, China \\ ${ }^{2}$ College of Art and Design, Shaanxi University of Science and Technology, Xi'an, China \\ 4606esust. edu.cn
}

\begin{abstract}
Enhancing teachers' visual digital media design ability is conductive to improving the effectiveness of classroom teaching of art design major. Thoroughly exploring, discussing, and studying the correlation between teachers' visual digital media design ability and effective teaching is a requirement for the professional development of art design teachers, and it is a very meaningful job for cultivating high-quality art design professionals. To this end, this paper aims to study the correlation between teachers' visual digital media design ability and effective teaching. At first, this paper constructed an Evaluation Index System (EIS) for evaluating teachers' visual digital media design ability, and gave the calculation methods and steps of the evaluation model based on the entropy weight TOPSIS method; then, the paper employed a Bayesian Convolutional Neural Network (BCNN) and made predictions on the multi-dimensional contribution of teachers' visual digital media design ability to effective teaching through the fusion of evaluation elements. At last, the effectiveness of the constructed EISs and models was verified by experimental results.
\end{abstract}

Keywords—digital media design, teacher quality, effective teaching, correlation analysis

\section{Introduction}

Teachers are crucial for cultivating talents that could fit in the requirements of the society, and they are precious human resources in the field of education [1-3]. Measures of a teacher's overall quality and level generally include the work competence, work efficiency, and other abilities and qualities [4-7]. In this new era, in order to adapt to the development needs of schools and students, modern education often requires teachers to master contemporary educational concepts, teaching ability, scientific research ability, and advanced teaching methods, and be able to improve their own qualities and abilities via various channels [8-10]. Specific to the art design major, improving art design teachers' visual digital media design ability is conductive to improving the effectiveness of classroom teaching of art design major, and realizing 
the goal of teaching quality improvement of the said major [11-15]. Therefore, thoroughly exploring, discussing, and studying the correlation between teachers' visual digital media design ability and effective teaching is a requirement for the professional development of art design teachers, and it is a very meaningful job for cultivating high-quality art design professionals.

With the progress of education reform, more emphases have been laid on classroom teaching quality. Cui [16] pointed out that only by continuously improving classroom teaching efficiency could we truly alleviate burdens on students, then, the scholar applied big data to analyze the characteristics and problems of classroom teaching behaviors and proposed improvement strategies in a targeted manner. Klimova [17] introduced the effectiveness of blended learning approach in teaching English as a foreign language to students in their third year of study at the Faculty of Informatics and Management of the University of Hradec Kralove, Czech Republic. Effective teaching is an educational idea. Previous scholars usually adopt speculative research methods to studying effective teaching based on the researcher's subjective judgment and teaching experience, so their research results are not supported by objective data, and it's difficult to determine whether the teaching is effective or not. Chen and Geng [18] proposed that evaluation data is a subset of education big data, which contain the data of the learning process and learning outcome of students produced during the daily practices and tests; they divided data into six stages: use a precise positioning teaching starting point; customize learning objectives made individually; select teaching content dynamically; adjust teaching strategies flexibly; use multidimensional evaluation and instant feedback; and recommend personalized learning resources; after that, they put forward specific operation strategies for every stage. Starting from the concept of the cutting-edge virtual reality technology, Shi [19] combined with the connotation and essence of effective teaching to analyze the teaching mode of "virtual reality + augmented reality" that can be used in current classroom teaching, and further explained the key points in operation and the reasonableness. Chen [20] studied the effective teaching of flipped classroom, by reviewing relevant literatures, the scholar analyzed the main characteristics of flipped classroom in detail, and gave an in-depth analysis to the positive role of flipped classroom in improving the teaching efficiency of higher educational schools.

After sorting out the existing research results, it's found that current studies on the relevance of effective teaching mainly include the relevance to classroom pattern, the relevance to teaching design ability, the relevance to error answer management, and the relevance to teacher's temperament, etc., and few of them targeted at specific information-based teaching methods of professional teachers or the ability to use professional software. To this end, this paper aims to research the correlation between teachers' visual digital media design ability and effective teaching. In the second chapter, this paper took "using teachers' visual digital media design ability to promote effective teaching" as the research content; built an EIS with 2 first-level (objective layer) indexes, 8 second-level (criterion layer) indexes, and 20 third-level (alternative layer) indexes; and gave the calculation methods and steps of the evaluation model based on the entropy weight TOPSIS method. In the third chapter, this paper analyzed the correlation between teachers' visual digital media design ability and effective 
teaching, and employed BCNN to predict the multi-dimensional contribution of teachers' visual digital media design ability to effective teaching through the fusion of evaluation elements. In the fifth chapter, this paper used experimental results to verify the effectiveness of the constructed EISs and models.

\section{Evaluation of teachers' visual digital media design ability}

Introducing Photoshop and 3Dmax into the teaching of art design classrooms can not only improve the classroom teaching effect of teachers and enhance the visual digital media design ability of students, but also better display the teaching content of traditional classrooms and give students more intuitive feelings.

This paper took "using teacher's visual digital media design ability to promote effective teaching" as the research content. Through surveys, experts' understanding of the evaluation of "using teachers' visual digital media design ability to promote effective teaching" and their suggestions on evaluation index selection were obtained. Then, according to the EIS construction principles and under the guidance of the dimension of the ability to use information technology in the information-based teaching transformation of art design major, this paper built an EIS containing 2 first-level (objective layer) indexes, 8 second-level (criterion layer) indexes, and 20 third-level (alternative layer) indexes. Details are given below:

The first level (objective layer):

$D M D=\left\{D M D_{1}, D M D_{2}\right\}=\{$ modeling ability, color design ability $\}$;

The second level (criterion layer):

$D M D_{1}=\left\{D M D_{11}, D M D_{12}, D M D_{13}, D M D_{14}\right\}=\{$ basic perception ability, ability to use light and shadow, model design ability, ability to integrate with other materials $\}$;

$D M D_{2}=\left\{D M D_{21}, D M D_{22}, D M D_{23}, D M D_{24}\right\}=\{$ color toning ability, color selection ability, image and color modification ability, overall image color matching ability ;

The third level (alternative layer):

$D M D_{11}=\left\{D M D_{111}, D M D_{112}, D M D_{113}, D M D_{114}, D M D_{115}\right\}=\{$ visual perception ability, auditory perception ability, taste perception ability, smell perception ability, tactile perception ability $\}$;

$D M D_{12}=\left\{D M D_{121}, D M D_{122}\right\}=\{$ ability to control light and shadow, light and shadow composition ability $\}$;

$D M D_{13}=\left\{D M D_{131}, D M D_{132}\right\}=\{$ ability to use points, lines, surfaces, and bodies, ability to create and modify model $\}$;

$D M D_{14}=\left\{D M D_{141}, D M D_{142}, D M D_{143}\right\}=\{$ material collection ability, material evaluation ability, material integration ability $\}$;

$D M D_{21}=\left\{D M D_{211}, D M D_{212}\right\}=\{$ RGB mode color toning ability, CMYK mode color toning ability $\}$;

$D M D_{22}=\left\{D M D_{221}, D M D_{222}\right\}=\{$ ability of using eyedropper tool to select color, ability of using Color Range command to select color\};

$D M D_{23}=\left\{D M D_{231}, D M D_{232}\right\}=\{$ ability of using imitate stamps to repair images, ability of using magic wand tool to change colors $\}$;

$D M D_{24}=\left\{D M D_{241}, D M D_{242}\right\}=\{$ hue adjustment ability, local color shaping ability $\}$. 
Based on the existing EISs and the entropy weight TOPSIS method, this paper built an evaluation model of teachers' visual digital media design ability for information-based teaching of art design major, here are the specific calculation methods and steps:

Step 1: Assuming that the number of teachers to be evaluated is $N$, the number of evaluation indexes is $M ; a_{i j}$ and $A_{i j}$ respectively represent the original value and normalized value of the $j$-th index of the $i$-th evaluation object; $a_{\text {min-ij }}$ and $a_{\text {max }-i j}$ respectively represent the minimum and maximum values of the i-th evaluation index of all evaluation objects. Formula 1 shows the calculation formula of data normalization:

$$
A_{i j}=d+\frac{a_{i j}-a_{\min -i j}}{a_{\max -i j}-a_{\min -i j}} \times r,(i=1,2, \ldots, N ; j=1,2, \ldots, M)
$$

Step 2: Calculate the entropy value of the $j$-th index based on Formula 2:

$$
S_{j}=-\frac{1}{\ln N}\left(\sum_{i=1}^{N} \eta_{i j} \ln \eta_{i j}\right),(i=1,2, \ldots, N ; j=1,2, \ldots, M)
$$
$3:$

The proportion $\eta_{i j}$ of the $j$-th index of the $i$-th object can be calculated by Formula

$$
\eta_{i j}=\frac{A_{i j}}{\sum_{i=1}^{N} A_{i j}}, 0 \leq S_{j} \leq 1,(i=1,2, \ldots, N ; j=1,2, \ldots, M)
$$

Step 3: Assuming that the variation coefficient is represented by $R_{j}$, calculate the weight of the $j$-th index based on Formula 4:

$$
Q_{j}=\frac{R_{j}}{\sum_{j=1}^{M} R_{j}},(i=1,2, \ldots, N ; j=1,2, \ldots, M)
$$

The coefficient of variation and the entropy value of evaluation index satisfy $R_{j}=1$ $S_{j}$, that is, the smaller the value of $R_{j}$, the larger the entropy value.

Step 4: Construct the weighted normalized matrix $G$, see the following formula:

$$
\begin{aligned}
& G=\left|g_{i j}\right|_{m n}=Q_{j} \times A_{i j},(i=1,2, \ldots, N ; j=1,2, \ldots, M) \\
& G=\left[\begin{array}{cccc}
g_{11} & g_{12} & \cdots & g_{1 M} \\
g_{21} & g_{22} & \cdots & g_{2 M} \\
\vdots & \vdots & \vdots & \vdots \\
g_{N 1} & g_{N 2} & \cdots & g_{N M}
\end{array}\right]=\left[\begin{array}{cccc}
Q_{1} A_{11} & Q_{2} A_{12} & \cdots & Q_{M} A_{1 M} \\
Q_{1} A_{21} & Q_{2} A_{22} & \cdots & Q_{1} A_{2 M} \\
\vdots & \vdots & \vdots & \vdots \\
Q_{1} A_{N 1} & Q_{2} A_{N 2} & \cdots & Q_{M} A_{M N}
\end{array}\right]
\end{aligned}
$$

Step 5: Determine positive and negative ideal solutions $g_{j}{ }^{+}$and $g_{j}{ }^{-}$according to Formulas 6 and 7: 


$$
\begin{aligned}
& g_{j}^{+}=\max \left\{g_{1 j}, g_{2 j}, \ldots g_{N j}\right\} \\
& g_{j}^{-}=\min \left\{g_{1 j}, g_{2 j}, \ldots g_{N j}\right\}
\end{aligned}
$$

Step 6: Calculate the Euclidean distance from the teacher to be evaluated to $g_{j}{ }^{+}$and $g_{j}^{-}$, which are represented by $E_{j}^{+}$and $E_{j}^{-}$, then there are:

$$
\begin{aligned}
& E_{i}^{+}=\sqrt{\sum_{j=1}^{M}\left(g_{i j}-g_{j}^{+}\right)^{2}},(i=1,2, \ldots, N ; j=1,2, \ldots, M) \\
& E_{i}^{-}=\sqrt{\sum_{j=1}^{M}\left(g_{i j}-g_{j}^{-}\right)^{2}},(i=1,2, \ldots, N ; j=1,2, \ldots, M)
\end{aligned}
$$

Step 7: The relative closeness $T D$ between the teacher to be evaluated and the ideal solution can be calculated by Formula 10:

$$
T D_{i}=\frac{E_{i}^{-}}{E_{i}^{+}+E_{i}^{-}},(i=1,2, \ldots, N ; j=1,2, \ldots, M)
$$

The value range of $T D_{i}$ is $[0,1]$. The size of $T D_{i}$ can be taken as the reference for evaluating and ranking the teachers' visual digital media design ability in the information-based teaching of art design major. Larger $T D_{i}$ value indicates that a teacher has a strong ability of visual digital media design, and the evaluation result will be better. Conversely, smaller $T D_{i}$ value indicates that a teacher has a poor ability of visual digital media design, and the evaluation result will be worse, and the room for improvement is bigger.

\section{Study of correlation and construction of contribution value evaluation model}

There is a complex heterogeneous relationship between the criteria for evaluating teachers' visual digital media design ability and the effective teaching. The value of teachers' visual digital media design ability is often hidden in such complex correlations. In different correlation network scenarios, elements of effective teaching will be integrated, therefore, there are certain differences in the reflected ability value. When solving the problem of the prediction of teachers' visual digital media design ability, the traditional deep learning models generally have defects such as single dimension and low accuracy of prediction results; therefore, in order to objectively evaluate the contribution of teachers' visual digital media design ability to effective teaching, this paper adopted BCNN and made predictions on the multi-dimensional contribution of teachers' visual digital media design ability to effective teaching through the fusion of evaluation elements. 
Traditional graph convolutional networks are mainly used to assist in solving the problem of graph structure data in social networks and information networks. Assuming: $H=(m, t)$ represents an unweighted undirected graph composed of a series of nodes $m$ and a set of edges $t$. In graph $H, a_{i}$ and $b_{i}$ respectively represent the eigenvector and the label corresponding to each node $i, A$ represents the eigenmatrix formed by eigenvectors, here the eigenvectors correspond to the evaluation indexes one by one.

In common classification and regression models, label $b_{i}$ might be a classification category or a real value. Assuming: $a$ represents the feature of unlabeled nodes in the unweighted undirected graph $H, H^{*}$ represents the observable graph described by adjacency matrix, then, the goal of the constructed graph convolutional neural network is to predict the labels of unlabeled nodes based on $a$ and $H^{*}$, and the prediction tasks could be completed by performing graph convolution operations.

Assuming: $\omega^{k}$ represents the weight of the $k$-th layer of the network, $\lambda^{k}$ represents the output feature of the $k$-1-th layer, $B O_{H}$ represents the adjacency matrix in graph $H$, $F O=\lambda^{k}$ represents the final output of the $k$-th layer, then the propagation mode between layers of the graph convolutional neural network can be described by Formula 18:

$$
\begin{aligned}
& \lambda^{1}=\varepsilon\left(B O_{H} A \omega^{0}\right) \\
& \lambda^{(k+1)}=\varepsilon\left(B O_{H} \lambda^{1} \omega^{k}\right)
\end{aligned}
$$

In a graph convolutional neural network, the information of neuron nodes in the next layer could be obtained by taking the weighted sum of the information of neuron nodes in the previous layer and the information of neighbor neuron nodes, and then processed by the nonlinear activation function $\varepsilon($.$) . The back-propagation algorithm$ could be adopted to complete the training of network weight $\omega$, and minimize the error between observed label $B$ and network output $F O$.

Below is the modeling of the study problem. Assuming: $G C=\left\{c_{M}\right\}_{M=1}^{|G C|}$ represents the evaluation object of the contribution value of teachers' visual digital media design ability to be evaluated to the corresponding elements of effective teaching, $G C^{*}=\left\{c^{*}{ }_{M}\right\}_{M=1}{ }^{\left|G C^{*}\right|}$ represents labeled evaluation objects, $a^{c}$ represents the feature of $c$, $b^{c}$ represents the value of $c, p^{c}$ represents the type of $c, G C-G C^{*}$ represents unlabeled evaluation objects, $A=\left\{a^{c} \mid c \in G C-G C^{*}\right\}$ represents the feature of $G C-G C^{*}$, $B=\left\{b^{c} \mid c \in G C-G C^{*}\right\}$ represents the multi-dimensional contribution value of teachers' visual digital media design ability to effective teaching, $P=\left\{p_{N}\right\}_{N=1}{ }^{|P|}$ represents the set of the types of effective teaching, $u\left(c, c^{-}\right)$represents the weight of $\left(c, c^{-}\right), G E^{*}=\{G C, U\}$ represents observable art design classroom teaching evaluation scenarios, $G E=\{G C, U\}$ represents generated evaluation scenarios, $\alpha^{p}{ }_{\omega}$ represents the accuracy parameter of network weight $\omega, \alpha^{p}{ }_{B}$ represents the accuracy parameter of label $B$, $B=\left\{b^{c} \mid c \in G C-G C^{*}\right\}$ represents the labeled value of $G C-G C^{*}, U=\left\{u^{c, c-} \mid c \in G C, c<c^{-}\right\}$ represents the set of correlations between $G C \mathrm{~s}, B^{*}=\left\{b^{c} \mid c \in G C^{*}\right\}$ represents the labeled value of $G C^{*}, A^{*}=\left\{a^{c} \mid c \in G C^{*}\right\}$ represents the feature of $G C^{*}, \omega_{k}=\left\{\omega_{i, j, k} \mid k \in K\right\}$ represents the weight matrix of the $k$-th layer, $\omega=\left\{\omega^{p} k \mid p \in P, k \in K\right\}$ represents the weight matrix of type $P, \alpha^{p}=\left\{\alpha_{Q}^{p}, \alpha_{B}^{p} \mid p \in P\right\}$ represents the accuracy parameter of $p$, 
$\Psi=\left\{\alpha^{p} \mid p \in P\right\}$ represents a set of accuracy parameter of $P, K=\left.\left\{k_{i}\right\}^{|K|}\right|_{i=1}$ represents the layer of the weight matrix, $V=\left\{v^{(p, p-)} \mid p \in P, p<p^{-}\right\}$represents the intensity set between type $P, \varphi=\left\{\varphi^{c} i \mid c \in G C, 1 \leq i \leq L\right\}$ represents the structural parameters of $G E$, then the probability distribution of $B=\left\{b^{c} \mid c \in G C-G C^{*}\right\}$ can be determined by the following formula:

$$
\begin{gathered}
R F\left(B \mid A, G E^{*}, G C^{*}\right)=\int R F\left(B \mid A, \omega, G E, \Psi_{\alpha}\right) R F\left(\omega, \Psi \mid G C^{*}, G E\right) \\
R F(G E \mid \phi, V) R F\left(\phi, V \mid G E^{*}\right) \\
d G E d \phi d \omega d \Psi d V \\
R F\left(B \mid A, \omega, G E, \Psi_{\alpha}\right)=\prod_{c \in G C} \prod_{l=1}^{L} R F\left(b_{l}^{c} \mid a^{c}, \omega^{p^{c}}, G E, \alpha_{B}^{p^{c}}\right) \\
R F\left(\omega, \Psi \mid G C^{*}, G E\right)=\frac{R F\left(B^{*} \mid A^{*}, \omega, G E, \Psi_{B}\right) R F\left(\omega \mid \Psi_{\omega}\right) R F(\Psi)}{R F\left(B^{*} \mid A^{*}\right)} \\
R F\left(\omega \mid \Psi_{\omega}\right)=\prod_{p \in P} R F\left(\omega^{p} \mid \alpha_{\omega}^{p}\right) \\
R F(\Psi)=\prod_{p \in P} R F\left(\alpha^{p}\right)
\end{gathered}
$$

Figure 1 gives a diagram of the contribution value evaluation model. Then, the Monte Carlo simulation method was adopted to approximate the reasoning of the model. For evaluation objects with an effective teaching type of $p$, an BCNN model $K F S$ was built for evaluating the contribution value of teachers' visual digital media design ability to effective teaching. Assuming: $\left|m_{p}\right|$ represents the number of neurons in the $K$-th layer, $E$ represents the unit matrix, $\sigma$ represents the inverse of the contrast of a noise term, then there are:

$$
\begin{gathered}
\operatorname{KFS}\left(B^{p}, \omega^{p} \mid A^{p}, G C^{*}, G E^{*}, \Psi^{p^{*}}, \phi^{*}, V^{*}\right) \\
V^{*}, \phi^{*}=\underset{V, \phi}{\operatorname{argmax}} R F\left(V, \phi \mid G E^{*}\right) \\
\Psi_{\omega_{k}^{p}}^{*}=\left\{\alpha_{\omega_{k}^{p}}^{*}(a, b) \mid k \in K, a \in f_{k}, b \in f_{k}\right\} \\
\alpha_{\omega_{k}^{*}}^{\alpha_{0}^{*}}(a, b)=\left|m_{k}\right|^{-1} \varepsilon(a) \varepsilon(b) \\
\Psi_{\omega_{k}^{p}}^{*}=\left\{\alpha_{\omega_{k}^{p}}^{*}(b) \mid b \in B\right\} \\
\alpha_{\omega_{k}^{p}}^{*}(b)=\sigma^{-1} E
\end{gathered}
$$




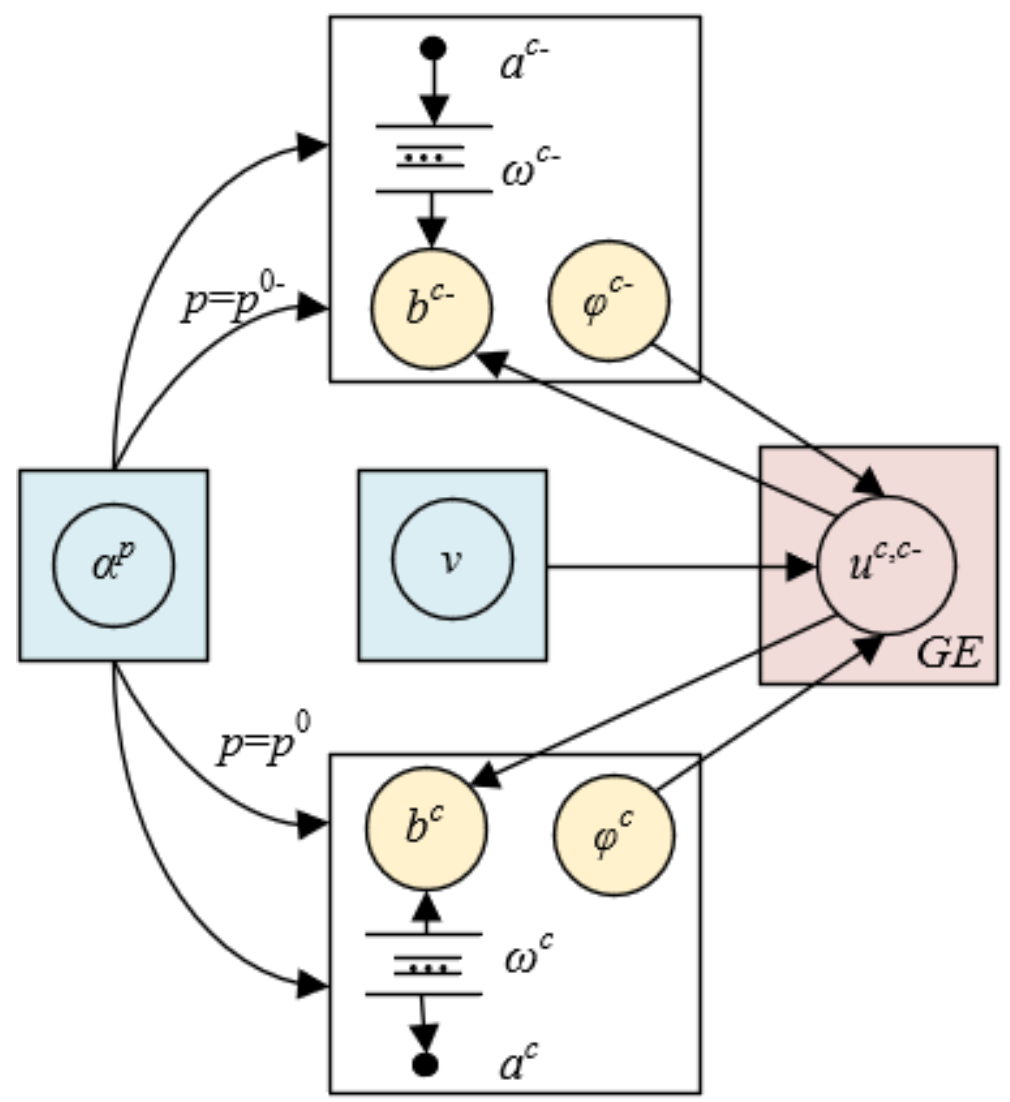

Fig. 1. A diagram of the contribution value evaluation model

After the evaluation model was determined, the posterior distribution of the multidimensional contribution values could be obtained based on Formula 28:

$$
\begin{aligned}
R F\left(B^{p} \mid A^{p}, G E^{*}, G C^{*}, \Psi^{p^{*}}, \phi^{*}, V^{*}\right)= & \int R F\left(B^{p} \mid A^{p}, \omega, \Psi^{p^{*}}\right) \\
& R F\left(\omega^{p} \mid G C^{*}, G E, \alpha_{\omega}\right) \\
& R F\left(G E \mid, \phi^{*}, V^{*}\right) \\
& d G E d \omega^{p}
\end{aligned}
$$

If parameters $A^{p}, G C^{*}, G E^{*}, \Psi^{*}, \varphi^{*}$, and $V^{*}$ are given, then the contribution of teachers' visual digital media design ability to effective teaching effect is generated by the following steps:

Step 1: Generate valuation scenario $G E \sim R F\left(G E \mid \varphi^{*}, V^{*}\right)$;

Step2: For $\omega=\left\{\omega^{p}{ }_{k} \mid p \in P, E \in K\right\}$, generate $\omega^{p}{ }_{k} \sim R F\left(\omega^{p}{ }_{k} \mid G C^{*}, G E\right)$; 
Step3: For $B=\left\{B^{p}\right\}$, generate $B^{p} \sim m\left(. g\left(\left(A^{p}, \omega^{p}, G E\right), \Psi^{p-1}{ }_{B}\right)\right.$, assuming: $f_{k}$ represents the output feature of the $k$-th layer, $B O^{G E}$ represents the adjacency matrix described by the evaluation scenario, then there are:

$$
\begin{aligned}
& g\left(A^{p} ; \omega^{p} ; G E\right)=f_{k} \\
& f_{k}=\varepsilon\left(B O^{G E} A^{p} \omega_{1}^{p}\right) \\
& f_{k}=\varepsilon\left(B O^{G E} f_{k-1} \omega_{1}^{p}\right)
\end{aligned}
$$

For the reasoning part of the model, based on the Monte Carlo approximation method, the posterior distribution of the multi-dimensional contribution of teachers' visual digital media design ability to effective teaching can be obtained by Formula 30:

$$
R F\left(B \mid A, G E^{*}, G C^{*}\right)=\frac{1}{|\tilde{G E}||\tilde{\omega}|} \sum_{g e_{i} \in G E} \sum_{\omega_{i j} \in \omega} R F\left(B \mid A, \omega_{i j}, g e_{i}, \Psi^{*}\right)
$$

Where,

$$
\begin{gathered}
\tilde{G E}=\left\{g e_{i}\right\}_{i=k}^{|\tilde{G E}|} ; \tilde{\omega}=\left\{\omega_{j}\right\}_{j=1}^{|\tilde{\omega}|} \\
g e_{i} \sim R F\left(g e_{i} \mid \phi^{*}, V^{*}\right) \\
\omega_{i j} \sim R F\left(\omega_{i j} \mid g e_{i}, G C^{*}\right)
\end{gathered}
$$

\section{Experimental results and analysis}

The construct validity of the EIS is also an important part of judging the effectiveness of the evaluation. Using exploratory factor analysis and confirmatory factor analysis, this paper tested the construct validity of the EISs constructed in this paper.

Table 1 shows the results of factor analysis of each evaluation criterion of teachers' visual digital media design ability. KMO values of the sampling appropriateness of the 8 evaluation criteria were $0.721,0.648,0.523,0.874,0.756,0.668,0.542,0.598$, respectively, indicating that the size of the original evaluation index sample set of teachers' visual digital media design ability was appropriate. In the Bartlett's test of sphericity, the chi-square test values were $254.36,315.25,232.10,352.01,256.28$, $184.23,199.87,244.28$, respectively, and the significance probability values were all $0.000<0.001$, indicating that the original evaluation index sample data were suitable for factor analysis. This paper adopted the principal component factor extraction method to process the evaluation criteria, and 8 common factors were successfully extracted. The eigenvalues were $1.789,2.441,2.356,2.414,2.036,2.368,1.955$, 
2.597, respectively, and the factor loads were all between 0.85 and 0.9 , indicating that the 8 common factors extracted can effectively reflect each evaluation index.

Table 1. Factor analysis of internal evaluation criteria of teachers' visual digital media design ability

\begin{tabular}{|l|c|c|c|c|}
\hline \multirow{2}{*}{ Evaluation criterion } & \multirow{2}{*}{ KMO test } & \multicolumn{3}{|c|}{ Bartlett's test of sphericity } \\
\cline { 3 - 5 } & & Chi-squared test & $\boldsymbol{d f}$ & Sig. \\
\hline $\mathrm{DMD}_{11}$ & 0.721 & 254.36 & 3 & 0.000 \\
\hline $\mathrm{DMD}_{12}$ & 0.648 & 315.25 & 4 & 0.000 \\
\hline $\mathrm{DMD}_{13}$ & 0.523 & 232.10 & 5 & 0.000 \\
\hline $\mathrm{DMD}_{14}$ & 0.874 & 352.01 & 5 & 0.000 \\
\hline $\mathrm{DMD}_{11}$ & 0.756 & 256.28 & 7 & 0.000 \\
\hline $\mathrm{DMD}_{22}$ & 0.668 & 184.23 & 6 & 0.000 \\
\hline $\mathrm{DMD}_{23}$ & 0.542 & 199.87 & 3 & 0.000 \\
\hline $\mathrm{DMD}_{24}$ & 0.598 & 244.28 & 3 & 0.000 \\
\hline
\end{tabular}

Table 2 lists the results of factor analysis of each internal evaluation criterion of effective teaching. For the 5 evaluation criteria of teaching goal, teaching content, teaching method, teaching form, and teaching effect, the KMO values of sampling appropriateness were $0.807,0.832,0.876,0.894$, and 0.925 , respectively, indicating that the size of the original sample set of evaluation indexes for teachers' effective teaching was appropriate. In the Bartlett's test of sphericity, the chi-square test values were 461.25, 434.56, 617.84, 697.56, 365.87, respectively, and the significance probability values were all $0.000<0.001$, indicating that the original evaluation index sample data were suitable for factor analysis. This paper also adopted the principal component factor extraction method to process the 5 evaluation criteria, and 5 common factors were successfully extracted. The eigenvalues were 2.347, 3.689, $3.877,6.241,4.365$, respectively, indicating that the 5 common factors extracted can effectively reflect each evaluation index.

Table 2. Factor analysis of internal evaluation criteria of effective teaching

\begin{tabular}{|l|c|c|c|c|}
\hline \multirow{2}{*}{ Evaluation criterion } & \multirow{2}{*}{ KMO test } & \multicolumn{3}{c|}{ Bartlett's test of sphericity } \\
\cline { 3 - 5 } & & Chi-squared test & $\boldsymbol{d f}$ & Sig. \\
\hline Teaching goal & 0.807 & 461.25 & 6 & 0.000 \\
\hline Teaching content & 0.832 & 434.56 & 8 & 0.000 \\
\hline Teaching method & 0.876 & 617.84 & 41 & 0.000 \\
\hline Teaching form & 0.894 & 697.56 & 5 & 0.000 \\
\hline Teaching effect & 0.925 & 365.87 & 6 & 0.000 \\
\hline
\end{tabular}

Table 3 gives the fit indexes of the structural equation models of teachers' visual digital media design ability and effective teaching. According to the table, the values of the Parsimony-based fit index CMIN/DF of the two EISs were 2.014 and 2.231, respectively, both less than 3 . The values of the absolute fit index of the two were 0.075 and 0.077 , respectively, both less than 0.08 . The values of the two parsimony- 
based indexes PGFI and PNFI were 0.824, 0.911 and 0.926, 0.824, respectively, both were greater than 0.5 . All relative fit indexes of the two EISs were higher than 0.9 . By referring to the standards of the overall goodness of fit of evaluation models, it can be verified that each fit index in Table 3 had met requirements, indicating that the fitting effect of the 8-dimensional evaluation of the teachers' visual digital media design ability and the 5-dimensional evaluation of effective teaching was good.

Table 3. Fit indexes of the structural equation models of teachers' visual digital media design ability and effective teaching

\begin{tabular}{|l|c|c|}
\hline \multicolumn{1}{|c|}{ Model } & Teachers' visual digital media design ability & Effective teaching \\
\hline Parsimony-based fit index CMIN/DF & 2.014 & 2.231 \\
\hline Absolute fit index & 0.075 & 0.077 \\
\hline Relative fit index NFI & 0.925 & 0.985 \\
\hline Relative fit index CFI & 0.924 & 0.963 \\
\hline Relative fit index TLI & 0.928 & 0.917 \\
\hline Relative fit index IFI & 0.984 & 0.837 \\
\hline Parsimony-based index PGFI & 0.824 & 0.911 \\
\hline Parsimony-based index PNFI & 0.926 & 0.824 \\
\hline
\end{tabular}

Reliability is an important indicator for judging the quality of an EIS. The higher the reliability of the EIS, the smaller the standard error of the evaluation, and the more reliable the evaluation results obtained. Cronbach's alpha can be used to measure the reliability of an EIS by calculating its internal consistency coefficient. Tables 4 and 5 respectively give the Cronbach's alpha of the EIS of teachers' visual digital media design ability and the EIS of effective teaching.

Table 4. Cronbach's alpha of the evaluation system of teachers' visual digital media design ability

\begin{tabular}{|l|c|}
\hline & Internal consistency \\
\hline Summary table & 0.934 \\
\hline DMD $_{11}$ & 0.851 \\
\hline DMD $_{12}$ & 0.758 \\
\hline DMD $_{13}$ & 0.805 \\
\hline DMD $_{14}$ & 0.862 \\
\hline DMD $_{11}$ & 0.815 \\
\hline DMD $_{22}$ & 0.795 \\
\hline $\mathrm{DMD}_{23}$ & 0.754 \\
\hline $\mathrm{DMD}_{24}$ & 0.895 \\
\hline
\end{tabular}


Table 5. Cronbach's alpha of the evaluation system of effective teaching

\begin{tabular}{|l|c|}
\hline & Internal consistency \\
\hline Summary table & 0.963 \\
\hline Teaching goal & 0.848 \\
\hline Teaching content & 0.827 \\
\hline Teaching method & 0.842 \\
\hline Teaching form & 0.832 \\
\hline Teaching effect & 0.904 \\
\hline
\end{tabular}

According to Tables 3-5, the overall internal consistency coefficient of the EIS of teachers' visual digital media design ability was 0.934 , and the overall internal consistency coefficient of the EIS of effective teaching was 0.963 , indicating the overall reliability of the two EISs is very ideal. The internal consistency coefficients of the former 8 evaluation criteria were $0.851,0.758,0.805,0.862,0.815,0.795,0.754$, 0.895 , respectively; and the internal consistency coefficients of the latter 5 evaluation criteria were $0.848,0.827,0.842,0.832,0.904$, respectively. The internal consistency coefficients of all evaluation criteria in the EISs were above 0.75, indicating that the reliability of the evaluation criteria in the EISs was good.

Using different data sources, this paper compared the proposed contribution value evaluation model with the reference model of a binary neural network. Since there's no reference value that could be taken as the standard for evaluating the contribution of teachers' visual digital media design ability to effective teaching, this paper replaced the reference with the incremental value of the effect of effective teaching.

This paper compared the mean absolute error and mean relative error of the proposed contribution value evaluation model and the reference model on two data sample sets, and the results are given in Table 6. According to the data in the table, the proposed model outperformed the reference model in terms of evaluation accuracy on both datasets.

Table 6. Errors of the contribution value of different models

\begin{tabular}{|l|c|c|c|c|}
\hline \multicolumn{1}{|c|}{ Data source } & \multicolumn{2}{c|}{ School 1 } & \multicolumn{2}{c|}{ School 2 } \\
\hline Error type & Mean absolute error & Mean relative error & Mean absolute error & Mean relative error \\
\hline Reference model & 112.03 & 1.652 & 88.293 & 2.354 \\
\hline Proposed model & 60.251 & 0.582 & 36.012 & 1.205 \\
\hline
\end{tabular}

In addition, this paper also compared the fluctuation of mean relative error of the contribution of teachers' visual digital media design ability to effective teaching within the value range of $(0,600]$. Table 7 and Figure 2 give the comparison results.

Table 7. Changes in evaluation errors within different contribution value ranges

\begin{tabular}{|c|c|c|c|c|c|c|}
\hline Range & $\mathbf{( 0 - 1 0 0 ]}$ & $\mathbf{( 1 0 0 - 2 0 0 ]}$ & $\mathbf{( 2 0 0 - 3 0 0 ]}$ & $\mathbf{( 3 0 0 - 4 0 0 ]}$ & $\mathbf{( 4 0 0 - 5 0 0 ]}$ & $\mathbf{( 5 0 0 - 6 0 0 ]}$ \\
\hline Reference model & 2.865 & 1.125 & 0.759 & 0.825 & 0.826 & 0.927 \\
\hline Proposed model & 0.925 & 0.224 & 0.548 & 0.668 & 0.758 & 0.825 \\
\hline
\end{tabular}




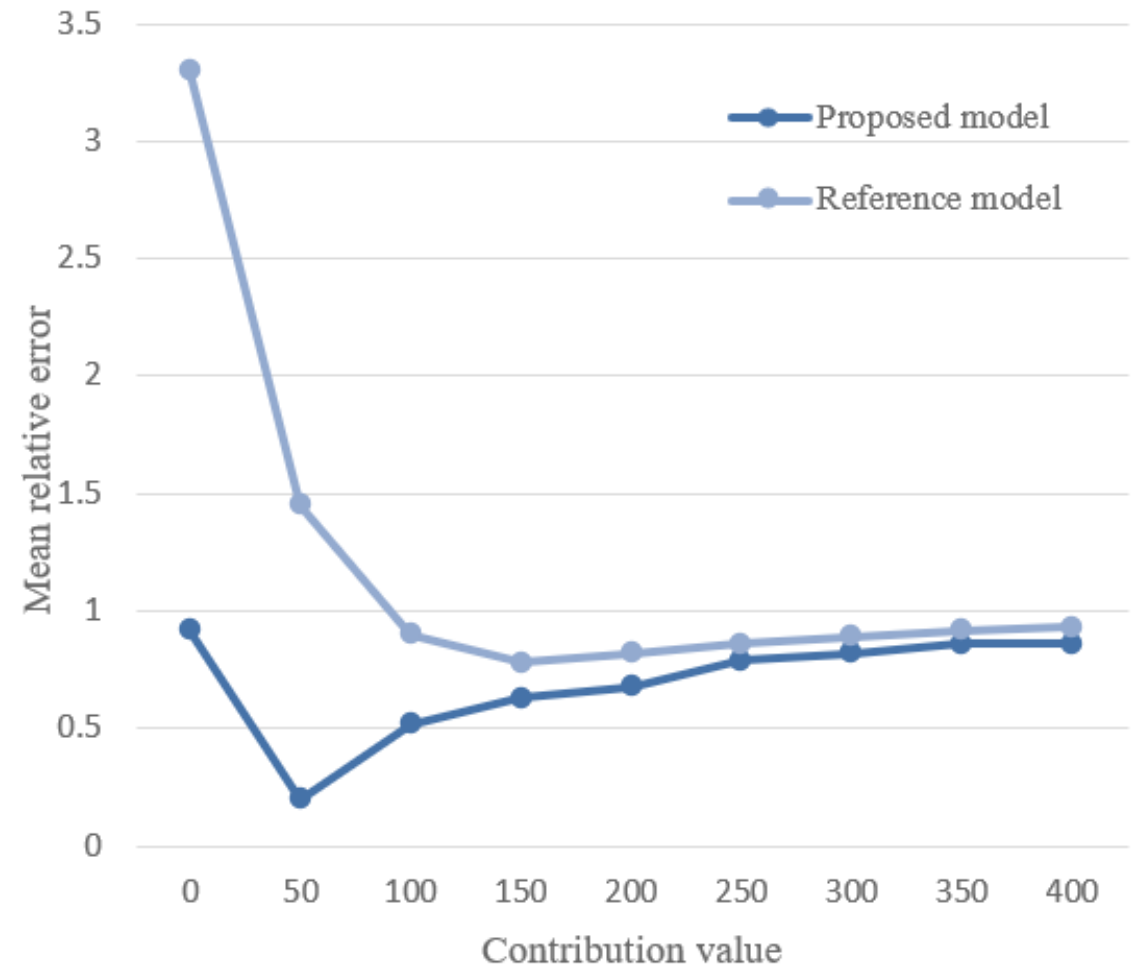

Fig. 2. Errors of contribution value of different models

Compared with the reference model, the mean relative error of the proposed model was smaller in different contribution value ranges, which had verified the effectiveness of the model constructed in this paper.

\section{Conclusion}

This paper studied the correlation between teachers' visual digital media design ability and effective teaching. At first, this paper constructed an EIS for evaluating teachers' visual digital media design ability and gave the calculation methods and steps of the evaluation model. Then, a BCNN was employed to evaluate the multidimensional contribution of teachers' visual digital media design ability to effective teaching. After that, for the evaluation system of teachers' visual digital media design ability and the evaluation system of effective teaching, this paper performed factor analysis and calculated the fix indexes and Cronbach's alpha of the models, and experimental resulted proved that the reliability of the evaluation criteria in the EISs was good. Moreover, the evaluation errors of the contribution value of different models were compared, and evaluation errors of the contribution value of different models within different value ranges were compared as well, the results showed that the mean relative error of the proposed model was smaller than the that of the reference model 
within different contribution value ranges, which had demonstrated the effectiveness of the proposed model.

\section{$6 \quad$ References}

[1] Wu, B., Hu, Y., Wang, M. (2019). Scaffolding design thinking in online STEM preservice teacher training. British Journal of Educational Technology, 50(5): 2271-2287. https://doi. org/10.1111/bjet.12873

[2] Sveinbjörnsdóttir, B., Jóhannsson, S. H., Oddsdóttir, J., Sigurðardóttir, T. P., Valdimarsson, G.I., Vilhjálmsson, H.H. (2019). Virtual discrete trial training for teacher trainees. Journal on Multimodal User Interfaces, 13(1): 31-40. https://doi.org/10.1007/ $\underline{\text { s12193-018-0288-9 }}$

[3] Dibarbora, C. (2021). Computational models and experimental validation at the physics teacher training college using scilab and arduino ${ }^{\mathrm{TM}}$. In Journal of Physics: Conference Series, 1882(1): 012139. https://doi.org/10.1088/1742-6596/1882/1/012139

[4] Chiu, C.F. (2020). Facilitating K-12 Teachers in Creating Apps by Visual Programming and Project-based Learning, International Journal of Emerging Technologies in Learning, 15(1): 103-118. https://doi.org/10.3991/ijet.v15i01.11013

[5] Gao, F. (2020). Establishment of college English teachers' teaching ability evaluation based on Clementine data mining. Journal of Intelligent \& Fuzzy Systems, 38(6): 68336841. https://doi.org/10.3233/JIFS-179761

[6] Metruk, R. (2020). Confronting the Challenges of MALL: Distraction, Cheating, and Teacher Readiness, International Journal of Emerging Technologies in Learning, 15(2): 414. https://doi.org/10.3991/ijet.v15i02.11325

[7] Luo, X. (2021). Quantitative Analysis on the Evaluation Indicators of Teaching Abilities of Physical Education Teachers in Colleges and Universities. International Journal of Emerging Technologies in Learning, 16(18): 143-155. https://doi.org/10.3991/ijet.v16i $\underline{18.25661}$

[8] Niu, G. (2010). Establish a formative evaluation index system of college english teachers' online teaching ability based on AHP. In 2010 Second International Conference on Computational Intelligence and Natural Computing, 1: 170-173. https://doi.org/10. 1109/CINC.2010.5643865

[9] Lin, H., Huang, M. (2020). Improving Strategies for Information-Based Educational and Teaching Abilities of Newly Appointed College Teachers Using the TPACK Hierarchical Model. International Journal of Emerging Technologies in Learning (iJET), 15(14): 220235. https://doi.org/10.3991/ijet.v15i14.15307

[10] Shen, G. (2018). Effect of Macro Environment on the Development of College English Teachers' Information-based Teaching Ability. International Journal of Emerging Technologies in Learning, 13(12): 201-210. https://doi.org/10.3991/ijet.v13i12.8278

[11] Sun, Y., Li, F., Zhang, Z. (2019). Promotion of Information Technology Teaching Ability of Food Specialty Teachers. In International Conference on Application of Intelligent Systems in Multi-modal Information Analytics, 1397-1402. https://doi.org/10.1007/978-3030-15740-1_176

[12] Martínez-Argüello, L.D., Hinojo-Lucena, F.J., Díaz, I.A. (2018). Application of Information and Communication Technologies (ITC) in teaching-learning processes by chemistry teachers. Inf. Tecnol, 29: 41-52. https://doi.org/10.4067/S0718-07642018000200041 
[13] Ito, K. (2019). A practice and evaluation of "Pictogramming" from the viewpoint of design and art education. In 2019 IEEE Frontiers in Education Conference (FIE), 1-6. https:// doi.org/10.1109/FIE43999.2019.9028564

[14] Liang, J. (2021). Current State of Art Design Education in Colleges and a New Hybrid Learning Mode. International Journal of Emerging Technologies in Learning, 16(17): 120133. https://doi.org/10.3991/ijet.v16i17.25651

[15] Cao, J., Li, G. (2018). The Innovation of CAI in Art Design Education. In International Conference on Frontier Computing, 542: 1169-1174. https://doi.org/10.1007/978-981-133648-5_150

[16] Cui, Y. (2021). Exploration of Teachers' Effective Teaching Behavior in Mathematics Classroom Based on Big Data Analysis. In Journal of Physics: Conference Series, 1744(4): 042077. https://doi.org/10.1088/1742-6596/1744/4/042077

[17] Klimova, B. (2021). Blended Learning as an Effective Approach to English Language Teaching at the Institutions of Higher Learning-A Case Study. Advanced Multimedia and Ubiquitous Engineering, 716: 115-120. https://doi.org/10.1007/978-981-15-9309-3_17

[18] Chen, M., Geng, N. (2019). Research on Effective Teaching based on Students' Assessment Data Analysis. In 2019 Eighth International Conference on Educational Innovation through Technology (EITT), 206-209. https://doi.org/10.1109/EITT.2019. $\underline{00047}$

[19] Shi, P. (2019). Research on Effective Teaching in the Vision of Virtual Reality. In Proceedings of the 2019 The 3rd International Conference on Digital Technology in Education, 44-47. https://doi.org/10.1145/3369199.3369240

[20] Chen, Z. (2017). A Study on the Effective Teaching of Flipped Class. AGRO Food Industry Hi-Tech, 28(1): 2971-2973.

\section{$7 \quad$ Authors}

Lin Shao, associate professor and doctoral candidate at Hebei Vocational University of Technology and Engineering, visiting scholar at Capital Normal University, and researcher at Visual Design and Education Institute, Capital Normal University, has been engaged in the teaching and research of visual art design for 21 years, and hosted/participated in more than 10 research projects at provincial level or above. His works have been exhibited multiple times at home and abroad, and awarded certificates of honor (Email: shaolin7607@126.com).

Wendi Zhang, lecturer and master student at Hebei Vocational University of Technology and Engineering, has been engaged in design art (visual communication design and theories), and hosted three research projects at provincial level or above. Under her instructions, her students have won multiple art design awards (Email: 921355192@qq.com).

Aiping Li, associate professor and doctoral candidate at Hebei Vocational University of Technology and Engineering, has been engaged in the teaching and research of digital media art design for two decades, and participated in two national projects and multiple provincial projects. She also serves as member and video engineer of China Folklore Photographic Association, director of Xindu District New Media Alliance, Xingtai, Hebei Province, and Adobe Certified Expert (Email: aipingli28@126.com). 
Feng Xin, Chinese ceramic artist, faculty member at College of Art and Design, Shaanxi University of Science and Technology, and guest teacher at Yunnan University, Hebei Academy of Fine Arts, and Guangzhou University. She also serves as judge of China Ceramic Art Design Competition, and member of Jiangxi Provincial Literary Critics Association.

Article submitted 2021-10-07. Resubmitted 2021-11-27. Final acceptance 2021-12-16. Final version published as submitted by the authors. 